\title{
Renal Replacement Therapy for Acute Kidney Injury
}

\author{
Heather Fieghen ${ }^{a}$ Ron Wald ${ }^{a}$ b Bertrand L. Jaber ${ }^{c}$ \\ aDivision of Nephrology, St. Michael's Hospital and the University of Toronto, and ' ${ }^{2}$ The Keenan Research Centre \\ in the Li Ka Shing Knowledge Institute of St. Michael's Hospital, Toronto, Ont., Canada; ' Division of Nephrology, \\ St. Elizabeth's Medical Center and Tufts University School of Medicine, Boston, Mass., USA
}

\section{Key Words}

Acute kidney injury $\cdot$ Biomarkers $\cdot$ Continuous renal replacement therapy $\cdot$ Intermittent hemodialysis • Sustained low-efficiency dialysis • Dialysis dose

\begin{abstract}
The treatment of established acute kidney injury (AKI) is largely supportive in nature. Renal replacement therapy remains the cornerstone of management for the minority of patients who have severe AKI. Optimization of renal replacement therapy may modulate the high mortality associated with AKI. Recent trials indicated that continuous renal replacement therapy does not confer a survival advantage as compared to intermittent hemodialysis. Furthermore, there is no evidence to support a more intensive strategy of renal replacement therapy in the setting of AKI. There is comparatively limited data regarding the ideal timing of renal replacement therapy initiation and the preferred mode of solute clearance.

Copyright $\odot 2009$ S. Karger AG, Base
\end{abstract}

\section{Introduction}

Acute kidney injury (AKI) is a frequent complication of hospitalization that is associated with substantial morbidity, mortality and health care expenditures [1, 2]. There is significant variability in the reported prevalence (1-25\%) and mortality (20-60\%) associated with AKI in hospitalized patients. This is to some extent related to the lack of a uniform definition for AKI. Two classification systems have emerged that may serve to unify communication concerning AKI (table 1) [3, 4]. The RIFLE classification system was formulated by the Acute Dialysis Quality Initiative and defines three strata of increasing severity of AKI: Risk, Injury and Failure, based on relative changes in serum creatinine and urine output, and two outcome strata (Loss and End-stage renal failure) [5]. The three-stage Acute Kidney Injury Network classification system largely overlaps with the three first stages of RIFLE, with the addition of an absolute serum creatinine increase of $0.3 \mathrm{mg} / \mathrm{dl}$ to qualify for stage 1 , a limit on the time interval for the creatinine rise to $48 \mathrm{~h}$, and categorization of patients started on renal replacement therapy (RRT) as stage 3 regardless of creatinine or urine output. In both classification systems, escalating severity of AKI is associated with incrementally worse outcomes [6].

Although understanding of the epidemiology of AKI has improved, there are no proven therapies that reverse the course of established AKI. RRT is a key component of the supportive care given to patients with severe AKI. Approximately $4 \%$ of all critically ill patients will require RRT [7]. Among RRT-requiring patients who survive the critical phase of their illness, the majority will be free of RRT at the time of hospital discharge [7, 8]. This review will discuss novel diagnostic strategies for AKI but will focus on the management of AKI, with an emphasis on renal replacement strategies.

\section{KARGER}

Fax +4161306 1234 E-Mail karger@karger.ch www.karger.com

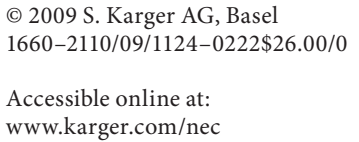

Ron Wald, MDCM, MPH

Division of Nephrology, St. Michael's Hospital

61 Queen Street East, 9th Floor

Toronto, Ont. M5C 2T2 (Canada)

Tel. +1 416867 3703, Fax +1 416867 3709, E-Mail waldr@smh.toronto.on.ca 
Table 1. The Acute Dialysis Quality Initiative and Acute Kidney Injury Network classification systems for AKI

\begin{tabular}{|c|c|c|}
\hline Stage & Serum creatinine change & Urine output criteria \\
\hline \multicolumn{3}{|c|}{ Acute Dialysis Quality Initiative RIFLE criteria $[4,5]$} \\
\hline Risk & increase in serum creatinine of $1.5-2$ times baseline & less than $0.5 \mathrm{ml} / \mathrm{kg} / \mathrm{h}$ for more than $6 \mathrm{~h}$ \\
\hline Injury & increase in serum creatinine of $2-3$ times baseline & less than $0.5 \mathrm{ml} / \mathrm{kg} / \mathrm{h}$ for more than $12 \mathrm{~h}$ \\
\hline Failure & $\begin{array}{l}\text { increase in serum creatinine of }>3 \text { times baseline OR if baseline creatinine } \\
>4 \mathrm{mg} / \mathrm{dl} \text { any } 0.5 \mathrm{mg} / \mathrm{dl} \text { increase gualifies }\end{array}$ & $\begin{array}{l}\text { less than } 0.3 \mathrm{ml} / \mathrm{kg} / \mathrm{h} \text { for more than } 24 \mathrm{~h} \\
\mathrm{OR} \text { anuria for }>12 \mathrm{~h}\end{array}$ \\
\hline Loss & persistent need for RRT for $>4$ weeks & \\
\hline End-stage & persistent need for RRT for $>3$ months & \\
\hline \multicolumn{3}{|c|}{ Acute Kidney Injury Network criteria } \\
\hline 1 & $\begin{array}{l}\text { increase in serum creatinine of } 1.5-2 \text { times baseline OR } 0.3 \mathrm{mg} / \mathrm{dl} \\
\text { increase from baseline }\end{array}$ & less than $0.5 \mathrm{ml} / \mathrm{kg} / \mathrm{h}$ for more than $6 \mathrm{~h}$ \\
\hline 2 & increase in serum creatinine of $2-3$ times baseline & less than $0.5 \mathrm{ml} / \mathrm{kg} / \mathrm{h}$ for more than $12 \mathrm{~h}$ \\
\hline 3 & increase in serum creatinine of $>3$ times baseline OR if baseline creatinine & less than $0.3 \mathrm{ml} / \mathrm{kg} / \mathrm{h}$ for more than $24 \mathrm{~h}$ \\
\hline
\end{tabular}

\section{New Biomarkers in AKI}

Current diagnostic paradigms for AKI are limited by reliance on serum creatinine, which is affected by age, gender and muscle mass. In addition, elevations in serum creatinine may occur several days after the actual injury. The search for AKI biomarkers has focused on identifying alternatives to serum creatinine. Urinary neutrophil gelatinase-associated lipocalin (NGAL) and interleukin18 may provide insights into the cause of AKI $[9,10]$. Similarly, urinary and serum NGAL, serum cystatin C and urinary kidney injury molecule-1 (KIM-1) may facilitate the early diagnosis of AKI. KIM-1 also shows promise in predicting adverse events in patients with established AKI [11]. Ongoing studies are clarifying the role of these biomarkers in larger patient cohorts. Ultimately, it will need to be shown that integration of novel biomarkers into clinical decision-making impacts on patient-relevant outcomes.

\section{Pharmacological Treatment of AKI}

Pharmacological interventions in AKI have targeted the prevention of renal ischemia or modulation of the ensuing inflammatory or hormonal milieus. Low-dose dopamine, historically thought to improve renal perfusion and thus prevent AKI, has recently been shown in a metaanalysis to have no effect on mortality and RRT requirement [12]. Similarly, atrial natriuretic peptide (ANP), a vasoactive endogenous hormone that increases glomerular filtration by dilating afferent and constricting efferent arterioles, was felt to be a promising therapeutic option. Anaritide, an ANP analogue, was initially shown to have no effect on dialysis-free survival and caused increased rates of hypotension in a randomized controlled trial (RCT) of AKI of variable etiology when given at a dose of $200 \mathrm{ng} / \mathrm{kg} / \mathrm{min}$ [13]. However, in a small randomized study of 59 postcardiac surgery patients with AKI, anaritide at a lower dose (50 $\mathrm{ng} / \mathrm{kg} / \mathrm{min}$ ) was found to significantly increase the rate of 21-day dialysis-free survival [14]. A recent meta-analysis of 19 different RCTs showed a trend towards reduction of RRT requirement when ANP was used in the prevention of AKI, however an overall increase in mortality was observed when ANP was used in the treatment of established AKI (particularly with higher doses) [15].

Recombinant human insulin-like growth factor 1 showed encouraging results at reducing renal tubular apoptosis and inflammation in mice when administered immediately after renal ischemia [16]. In a small RCT of 72 critically ill patients with AKI, insulin-like growth factor 1 failed to show any benefit [17]. More recently, $\mathrm{N}$-acetylcysteine and sodium bicarbonate have received a great deal of attention in the setting of contrast nephropathy and postcardiac surgery AKI prevention [18, 19]. The clinical benefits of these interventions remain controversial.

There are a number of other agents in preclinical studies that show promise in the prevention or early treatment of AKI. However, the efficacy of these therapies in clinical practice may depend on the early identification of AKI [20]. 
Table 2. Practical comparison of acute RRT modalities

\begin{tabular}{lccc}
\hline & $\begin{array}{l}\text { Intermittent } \\
\text { hemodialysis }\end{array}$ & $\begin{array}{l}\text { Sustained low- } \\
\text { efficiency dialysis }\end{array}$ & $\begin{array}{l}\text { Continuous renal } \\
\text { replacement therapy }\end{array}$ \\
\hline $\begin{array}{l}\text { Session duration, } \mathrm{h} \\
\text { Blood flow, } \mathrm{ml} / \mathrm{min}\end{array}$ & $3-5$ & $8-12$ & 24 \\
$\begin{array}{l}\text { Dialysate flow, } \mathrm{ml} / \mathrm{min} \\
\text { Anticoagulation requirement }\end{array}$ & $300-400$ & $200-300$ & $100-200$ \\
$25-40$ & $200-350$ & heparin or none & heparin or regional citrate \\
\hline
\end{tabular}

Table 3. Results of individual RCTs comparing CRRT to IHD

\begin{tabular}{|c|c|c|c|c|c|c|c|}
\hline \multirow[t]{2}{*}{ Study } & \multicolumn{2}{|c|}{ Sample size } & \multirow[t]{2}{*}{ Primary endpoint } & \multicolumn{2}{|c|}{ Mortality, \% } & \multicolumn{2}{|c|}{$\begin{array}{l}\text { Persistent dialysis } \\
\text { requirement }{ }^{\mathrm{a}}, \%\end{array}$} \\
\hline & CRRT & IHD & & CRRT & IHD & CRRT & IHD \\
\hline Mehta et al. [21] & 84 & 82 & ICU mortality & 59.5 & 41.5 & 14.0 & 7.0 \\
\hline Augustine et al. [23] & 40 & 40 & in-hospital mortality & 67.5 & 70.0 & 61.5 & 66.7 \\
\hline Uehlinger et al. [24] & 70 & 55 & in-hospital mortality & 47.0 & 51.0 & 2.7 & 3.7 \\
\hline Vinsonneau et al. [22] & 175 & 184 & 60-day mortality & 67.4 & 68.5 & 1.8 & 0.0 \\
\hline Lins et al. [25] & 172 & 144 & in-hospital mortality & 58.1 & 62.5 & $16.9^{\mathrm{b}}$ & $25.5^{\mathrm{b}}$ \\
\hline
\end{tabular}

${ }^{a}$ Defined as dialysis dependence at the time of hospital discharge among survivors.

${ }^{\mathrm{b}}$ Glomerular filtration rate $<15 \mathrm{ml} / \mathrm{min}$ at the time of hospital discharge.

\section{RRT Modality Choice}

Intermittent hemodialysis (IHD), continuous renal replacement therapies (CRRT) and sustained low-efficiency dialysis (SLED) are the principal RRT modalities that are used in the acute setting. Although institutional policies may determine the local availability of these modalities, CRRT and SLED tend to be used in patients with greater hemodynamic instability. There is likely substantial intercenter variability with respect to how each of these forms of RRT is utilized and prescribed.

IHD is typically administered with conventional dialysis machinery that is used in the chronic dialysis population with session length ranging from 3 to $5 \mathrm{~h}$. CRRT is applied with an intended treatment time of $24 \mathrm{~h}$ and generally requires dedicated machines that operate at comparatively lower blood and dialysate pump speeds. CRRT may be administered as hemodialysis (continuous venovenous hemodialysis, CVVHD), hemofiltration (continuous venovenous hemofiltration, $\mathrm{CVVH}$ ) or a combination of these (continuous venovenous hemodiafiltration, CVVHDF). SLED, sometimes referred to as extended dialysis, is considered a 'hybrid' of IHD and
CRRT. SLED is administered using conventional dialysis technology but typical sessions run for 8-12 h using blood and dialysis flows that are intermediate to those prescribed in IHD and CRRT. Table 2 summarizes the differences between these three modalities.

\section{CRRT versus IHD}

Most trials that addressed the question of optimal RRT modality compared CRRT and IHD (table 3). A trial by Mehta et al. [21] revealed higher ICU mortality in patients treated with CRRT as compared to IHD (59.5 vs. 41.5\%). This finding was tempered by apparent baseline imbalances between the groups, whereby patients randomized to CRRT had a greater severity of illness. Renal recovery did not differ between the groups.

In a larger multicenter RCT conducted in France comparing CRRT and IHD in critically ill patients with AKI [22], 60-day mortality was not reduced by CRRT, and there was no significant difference in the duration of RRT dependence. Three additional trials have shown no survival benefit with CRRT [23-25].

The presumption of greater hemodynamic stability with CRRT also remains controversial. Three RCTs sug- 
gested no advantage with CRRT as compared to IHD [22, 24, 26], while others demonstrated more favorable hemodynamics with CRRT $[23,27]$. Even if CRRT confers a hemodynamic benefit, it is unclear whether this translates into improvements in the patient-relevant outcomes of survival and renal recovery.

\section{CRRT versus SLED}

In addition to the absence of a survival advantage, CRRT is more costly than IHD and is associated with a number of obstacles such as continuous patient immobilization, the requirement for anticoagulation and the need for specialized machines and premixed commercial solutions [28]. This has stimulated a search for a strategy that incorporates the putative hemodynamic benefits of CRRT without the associated logistic and resource constraints. SLED meets many of these criteria.

Observational data from single centers suggest that SLED is a feasible way of providing RRT that is adequate, hemodynamically well tolerated, potentially anticoagulation-free and possibly cost-effective [29, 30]. However, only two small RCTs have compared SLED and CRRT [31, 32]. Kielstein et al. [31] randomized 39 critically ill patients with AKI to receive either $24 \mathrm{~h}$ of $\mathrm{CVVH}$ or 12 $\mathrm{h}$ of SLED. Using invasive monitoring, these authors found no significant differences in all measured hemodynamic parameters (mean arterial pressure, systemic vascular resistance, cardiac output) with comparable removal of creatinine and urea. A smaller study randomized 16 patients to receive three sessions with either CVVH or SLED (with an added hemofiltration component), and showed that fluid removal and hemodynamic parameters were similar in both groups [32]. Although these preliminary data suggest that SLED may supplant CRRT as the modality of choice for hemodynamically unstable patients with AKI, further studies that utilize patient-relevant outcomes are required to define the precise role of SLED.

A strategy has recently been described whereby CRRT machinery was applied over a contracted treatment time of $9 \mathrm{~h}$, using increased blood and effluent flow rates. Termed accelerated venovenous hemofiltration, this modality retains many of the feasibility advantages of SLED, but dedicated commercial solutions were still required. A retrospective case series demonstrated adequate solute removal, acceptable hemodynamic tolerability and the ability to avoid systemic anticoagulation [33].

Renal Replacement Therapy for Acute Kidney Injury

\section{Intensity of RRT}

The impact of RRT intensity or dose on patient outcomes has been a matter of controversy. Most definitions of acute RRT dose are based on small molecule removal, as exemplified by urea, while ignoring other crucial aspects of RRT adequacy in AKI, such as volume and electrolyte control. Furthermore, assumptions pertaining to urea kinetic modeling that are applied to end-stage renal disease are inappropriate in the acute setting. Finally, many of the benefits derived from acute RRT may relate to large-molecular-weight solute clearance, which is poorly quantified.

Schiffl et al. [34] compared daily to thrice-weekly IHD in 146 critically ill patients with AKI. Patients receiving daily hemodialysis had significantly lower mortality as compared to those receiving alternate-day dialysis (28 vs. $46 \%)$ and a shorter time to renal recovery, as defined by independence from dialysis (mean of 9 vs. 16 days). The study was designed to provide a minimum $\mathrm{Kt} / \mathrm{V}_{\text {urea }}$ of 1.2 for each treatment session in both arms of the study. However, the authors demonstrated that the actual delivered dose per session was significantly lower than intended, albeit similar in both arms of the study (mean $\mathrm{Kt} / \mathrm{V}_{\text {urea }}$ of 0.92 vs. 0.94 ). It is therefore unclear if the survival benefit demonstrated in this study was mediated by the mere provision of an adequate dialysis dose in the daily dialysis arm or by the true merits of more intensive therapy.

Ronco et al. [35] randomized 425 critically ill patients with AKI to continuous hemofiltration rates of 20,35 or $45 \mathrm{ml} / \mathrm{kg} / \mathrm{h}$. They showed enhanced survival at 15 days following discontinuation of RRT in the two high-dose groups when compared to the low-dose group. The benefits of high-intensity CRRT were also seen in a trial by Saudan et al. [36] who compared CVVH (mean effluent flow of $25 \mathrm{ml} / \mathrm{kg} / \mathrm{h}$ ) with CVVHDF (mean effluent flow of $42 \mathrm{ml} / \mathrm{kg} / \mathrm{h}$ ) in 206 critically ill patients. Ninety-day survival was significantly higher among patients treated with CVVHDF as compared with CVVH (59 vs. 34\%). These results contrasted with two other trials demonstrating no benefit with intensified therapy $[37,38]$.

In the recently completed Veterans Administration/ National Institutes of Health Acute Renal Failure Trial Network (ATN) study, over 1,100 critically ill patients with AKI requiring RRT were randomized to an intensive or a less intensive treatment strategy [39]. In the intensive arm, hemodynamically unstable patients received CRRT at $35 \mathrm{ml} / \mathrm{kg} / \mathrm{h}$ or 6 sessions per week of SLED; if patients were hemodynamically stable, IHD was admin-

Nephron Clin Pract 2009;112:c222-c229 
istered 6 times per week. In the less intensive arm, hemodynamically unstable patients received CRRT at $20 \mathrm{ml} /$ $\mathrm{kg} / \mathrm{h}$ or thrice-weekly SLED; stable patients received thrice-weekly IHD. Patients were able to shift between RRT modalities depending on their evolving hemodynamic status, thereby reflecting usual clinical practice. The trial was well executed with minimal crossover and excellent follow-up. Sixty-day mortality was 53.6 and $51.8 \%$ in the intensive and less intensive arms, respectively (NS). There were no appreciable differences in renal recovery.

Two important limitations of the ATN study should be considered. In both treatment arms, CRRT was delivered as an equal mix of hemodialysis and hemofiltration. The benefits of more intensive RRT may be conferred by the latter component, and it is notable that hemofiltration was administered exclusively in the positive trial by Ronco et al. [35]. The generalizability of the ATN study is also limited by the exclusion of patients with significant premorbid chronic kidney disease, a population that comprises a large proportion of AKI patients seen in clinical practice $[7,40]$. The Randomised Evaluation of Normal vs. Augmented Level (RENAL) Replacement Therapy study (ClinicalTrials.gov identifier NCT00221013) enrolled 1,500 critically ill patients in Australia and New Zealand with AKI at multiple sites. Preliminary study results have been reported (although not published to date) and indicate that CVVHDF at a dose of $40 \mathrm{ml} / \mathrm{kg} / \mathrm{h}$ did not confer improved 90-day survival as compared to a dose of $25 \mathrm{ml} / \mathrm{kg} / \mathrm{h}$.

\section{Timing of RRT Initiation}

Conventional indications for RRT initiation in AKI include refractory hyperkalemia, severe metabolic acidosis, hypervolemia, and uremic end-organ complications. However, one or more of these indications may emerge well after the time of the kidney insult. The resulting delay in initiating RRT may prolong patient exposure to the uncorrected metabolic effects of kidney failure, which may in turn contribute to adverse outcomes.

There is a very limited evidence base to guide the timing of RRT initiation in AKI. A recent meta-analysis identified 23 relevant studies and found a wide array of study designs and definitions for 'early' and 'late' RRT initiation [41]. In the 5 RCTs that addressed this issue, early initiation of RRT was associated with a trend towards mortality reduction [risk ratio (RR) $0.64,95 \%$ confidence interval (CI) $0.40-1.05]$ and in the 18 observa- tional studies, a mortality risk reduction of $28 \%$ (RR 0.72 , 95\% CI 0.64-0.82) was observed. It is noteworthy that all of the RCTs cited in the meta-analysis had small sample sizes and were generally of poor quality.

Defining the optimal timing of RRT initiation in AKI remains a research priority. Prior to embarking on a definitive RCT, substantial preliminary work will be required to determine the prevailing standard of care in the timing of RRT initiation. This should set the parameters for the control arm in such a trial. An 'early start' strategy could then be derived relative to the standard of care.

\section{Convection and Removal of Large-Molecular-Weight Solutes}

Convection, as provided through hemofiltration, and diffusion, as provided through hemodialysis, are the principal modes of solute removal in AKI. Convection utilizes hydrostatic pressure to effect the translocation of water across the semi-permeable membrane while concomitantly dragging solutes with molecular weights that are below the pore size of the membrane. Diffusion fuels the movement of solutes across a semi-permeable membrane down concentration gradients for the respective solutes. Both modes provide reliable clearance of lowmolecular-weight molecules such as urea, whereas largermolecular-weight solutes are more effectively removed by convection. Large molecules of particular interest include inflammatory cytokines such as tumor necrosis factor- $\alpha$ and interleukin- 6 that may serve as key mediators in the pathogenesis of AKI. Despite the conceptual appeal of convective clearance, there is a paucity of patient-level data on the optimal mode of clearance in AKI resulting in a great deal of practice variability. A small RCT evaluated outcomes of 20 patients who received CVVH versus CVVHD. There were no significant differences in mortality, renal recovery or duration of ICU stay [42].

Removal of large-molecular-weight solutes may also be enhanced by the use of hemodiafilters with larger pore sizes. These so-called high cutoff hemodiafilters have pores of $50-60 \mathrm{kDa}$ (as compared to $20-30 \mathrm{kDa}$ for conventional hemodiafilters), thereby enabling the translocation of larger-sized inflammatory mediators. Haase et al. [43] recently completed a double-blind crossover RCT of 10 septic patients with AKI who received 4-hour sessions of hemodialysis with a high cutoff dialyzer and a standard high-flux dialyzer, respectively, in random se- 
quence. Interleukin-6, interleukin-8 and interleukin-10 concentrations were significantly reduced following therapy with the high cutoff dialyzers with little change in these markers following treatment with the high-flux dialyzer. Similar small solute control was achieved with both dialyzers. Although the clinical implications of these findings need further clarification, other work done by this group suggested improved hemodynamic control in patients treated with a high cutoff hemodiafilter [44].

\section{Renal Tubule Cell Therapy}

Contemporary RRT devices are designed to replace the filtration component of kidney function but tubular function is not addressed. Humes et al. [45] have developed a bioartificial kidney known as a renal assist device (RAD), composed of sheets of human tubular cells that are housed within a high-flux hemodiafilter. Preliminary data indicated that these cells successfully performed many of the transport and endocrinologic functions normally attributed to the renal tubular epithelium [46]. A phase II RCT of 58 critically ill patients with AKI compared $72 \mathrm{~h}$ of continuous treatment with the RAD and a conventional filter (in series with each other) versus conventional CRRT [47]. Treatment with the RAD was found to be safe with a trend towards reduced mortality at 28 days (33 vs. $61 \%$ in patients treated with conventional CRRT). The RR of death in the RAD group, adjusted for comorbid illness, was 0.48 (95\% CI $=0.23-0.99)$. In addition, higher rates of renal recovery were seen in patients treated with the RAD. It should be noted that only 10 of the 40 patients treated with RAD completed the planned $72 \mathrm{~h}$ of therapy.

\section{Conclusions}

New classification systems for AKI may enhance standardization around diagnosis and staging of this clinical syndrome. Novel biomarkers for the early diagnosis of AKI may represent a breakthrough for clinicians if they are accurate, reproducible and applicable in different settings. There are currently no specific therapeutic interventions for patients with established AKI.

It is possible that optimization of the RRT prescription will impact on patient outcomes. Recently completed RCTs have provided clinicians with guidance on some aspects of the RRT prescription but several areas remain unclear. Despite the conceptual advantages of CRRT, multiple RCTs have shown no evidence of improved patient outcomes with this modality, as compared to conventional IHD. The logistic challenges associated with CRRT and the relatively high costs of this modality may stimulate the increased use of SLED. However, well-designed RCTs are still needed to better characterize the reported benefits of SLED prior to its widespread adoption. Recent data have also clarified important questions regarding RRT intensity in AKI. The current balance of evidence suggests that among hemodynamically unstable patients, CRRT need not be administered at doses higher than $20 \mathrm{ml} / \mathrm{kg} / \mathrm{h}$, and in more stable patients, alternate-day IHD is acceptable.

There are several areas in the AKI arena where highquality evidence is lacking. The optimal timing of RRT initiation in AKI remains a critical area of uncertainty. A well-powered trial to examine this issue, in which an early intervention may be guided by novel AKI biomarkers, is needed. Further trials to address the clinical benefits conferred by convective clearance, high cutoff filters and the bioartificial kidney are also required.

\section{References}

1 Nash K, Hafeez A, Hou S: Hospital-acquired renal insufficiency. Am J Kidney Dis 2002; 39:930-936.

-2 Liangos O, Wald R, O'Bell JW, Price L, Pereira BJ, Jaber BL: Epidemiology and outcomes of acute renal failure in hospitalized patients: a national survey. Clin J Am Soc Nephrol 2006;1:43-51.

- 3 Mehta RL, Kellum JA, Shah SV, Molitoris BA, Ronco C, Warnock DG, Levin A: Acute kidney injury network: report of an initiative to improve outcomes in acute kidney injury. Crit Care 2007;11:R31.

-4 Bellomo R, Ronco C, Kellum JA, Mehta RL, Palevsky P: Acute renal failure - Definition,

Renal Replacement Therapy for Acute Kidney Injury outcome measures, animal models, fluid therapy and information technology needs: the Second International Consensus Conference of the Acute Dialysis Quality Initiative (ADQI) Group. Crit Care 2004;8:R204$\mathrm{R} 212$.

5 Ostermann M, Chang RW: Acute kidney injury in the intensive care unit according to RIFLE. Crit Care Med 2007;35:1837-1843; quiz 1852.

-6 Bagshaw SM, George C, Bellomo R: A comparison of the RIFLE and AKIN criteria for acute kidney injury in critically ill patients. Nephrol Dial Transplant 2008;23:15691574.
7 Uchino S, Kellum JA, Bellomo R, Doig GS, Morimatsu H, Morgera S, Schetz M, Tan I, Bouman C, Macedo E, Gibney N, Tolwani A, Ronco C: Acute renal failure in critically ill patients: a multinational, multicenter study. JAMA 2005;294:813-818.

-8 Bagshaw SM, Laupland KB, Doig CJ, Mortis G, Fick GH, Mucenski M, Godinez-Luna T, Svenson LW, Rosenal T: Prognosis for longterm survival and renal recovery in critically ill patients with severe acute renal failure: a population-based study. Crit Care 2005;9: R700-R709.

\footnotetext{
S
} 
-9 Nickolas TL, O’Rourke MJ, Yang J, Sise ME, Canetta PA, Barasch N, Buchen C, Khan F, Mori K, Giglio J, Devarajan P, Barasch J: Sensitivity and specificity of a single emergency department measurement of urinary neutrophil gelatinase-associated lipocalin for diagnosing acute kidney injury. Ann Intern Med 2008;148:810-819.

-10 Parikh CR, Jani A, Melnikov VY, Faubel S, Edelstein CL: Urinary interleukin-18 is a marker of human acute tubular necrosis. Am J Kidney Dis 2004;43:405-414.

-11 Liangos O, Perianayagam MC, Vaidya VS, Han WK, Wald R, Tighiouart H, MacKinnon RW, Li L, Balakrishnan VS, Pereira BJ, Bonventre JV, Jaber BL: Urinary N-acetylbeta-(D)-glucosaminidase activity and kidney injury molecule-1 level are associated with adverse outcomes in acute renal failure. J Am Soc Nephrol 2007;18:904-912.

-12 Friedrich JO, Adhikari N, Herridge MS, Beyene J: Meta-analysis: low-dose dopamine increases urine output but does not prevent renal dysfunction or death. Ann Intern Med 2005;142:510-524.

-13 Allgren RL, Marbury TC, Rahman SN, Weisberg LS, Fenves AZ, Lafayette RA, Sweet RM, Genter FC, Kurnik BR, Conger JD, Sayegh MH: Anaritide in acute tubular necrosis. Auriculin Anaritide Acute Renal Failure Study Group. N Engl J Med 1997;336: 828-834.

- 14 Sward K, Valsson F, Odencrants P, Samuelsson O, Ricksten SE: Recombinant human atrial natriuretic peptide in ischemic acute renal failure: a randomized placebo-controlled trial. Crit Care Med 2004;32:13101315.

-15 Nigwekar SU, Navaneethan SD, Parikh CR, Hix JK: Atrial natriuretic peptide for management of acute kidney injury: a systematic review and meta-analysis. Clin J Am Soc Nephrol 2009;4:261-272.

- 16 Goes N, Urmson J, Vincent D, Ramassar V, Halloran PF: Effect of recombinant human insulin-like growth factor-1 on the inflammatory response to acute renal injury. J Am Soc Nephrol 1996;7:710-720.

- 17 Hirschberg R, Kopple J, Lipsett P, Benjamin E, Minei J, Albertson T, Munger M, Metzler M, Zaloga G, Murray M, Lowry S, Conger J, McKeown W, O'Shea M, Baughman R, Wood K, Haupt M, Kaiser R, Simms H, Warnock D, Summer W, Hintz R, Myers B, Haenftling K, Capra W, et al: Multicenter clinical trial of recombinant human insulin-like growth factor I in patients with acute renal failure. Kidney Int 1999;55:2423-2432.

- 18 Birck R, Krzossok S, Markowetz F, Schnulle $\mathrm{P}$, van der Woude FJ, Braun C: Acetylcysteine for prevention of contrast nephropathy: meta-analysis. Lancet 2003;362:598-603.

$\checkmark 19$ Kelly AM, Dwamena B, Cronin P, Bernstein SJ, Carlos RC: Meta-analysis: effectiveness of drugs for preventing contrast-induced nephropathy. Ann Intern Med 2008;148:284294.
20 Jo SK, Rosner MH, Okusa MD: Pharmacologic treatment of acute kidney injury: why drugs haven't worked and what is on the horizon. Clin J Am Soc Nephrol 2007;2:356365.

21 Mehta RL, McDonald B, Gabbai FB, Pahl M Pascual MT, Farkas A, Kaplan RM: A randomized clinical trial of continuous versus intermittent dialysis for acute renal failure. Kidney Int 2001;60:1154-1163.

22 Vinsonneau C, Camus C, Combes A, Costa de Beauregard MA, Klouche K, Boulain T, Pallot JL, Chiche JD, Taupin P, Landais P, Dhainaut JF: Continuous venovenous haemodiafiltration versus intermittent haemodialysis for acute renal failure in patients with multiple-organ dysfunction syndrome: a multicentre randomised trial. Lancet 2006; 368:379-385.

23 Augustine JJ, Sandy D, Seifert TH, Paganini EP: A randomized controlled trial comparing intermittent with continuous dialysis in patients with ARF. Am J Kidney Dis 2004;44: 1000-1007.

24 Uehlinger DE, Jakob SM, Ferrari P, Eichelberger M, Huynh-Do U, Marti HP, Mohaupt MG, Vogt B, Rothen HU, Regli B, Takala J Frey FJ: Comparison of continuous and intermittent renal replacement therapy for acute renal failure. Nephrol Dial Transplant 2005;20:1630-1637.

25 Lins RL, Elseviers MM, Van der Niepen P, Hoste E, Malbrain ML, Damas P, Devriendt $\mathrm{J}$ : Intermittent versus continuous renal replacement therapy for acute kidney injury patients admitted to the intensive care unit: results of a randomized clinical trial. Nephrol Dial Transplant 2009;24:512-518.

26 Misset B, Timsit JF, Chevret S, Renaud B, Tamion F, Carlet J: A randomized cross-over comparison of the hemodynamic response to intermittent hemodialysis and continuous hemofiltration in ICU patients with acute renal failure. Intensive Care Med 1996;22:742746.

27 John S, Griesbach D, Baumgartel M, Weihprecht $\mathrm{H}$, Schmieder RE, Geiger $\mathrm{H}$ : Effects of continuous haemofiltration vs intermittent haemodialysis on systemic haemodynamics and splanchnic regional perfusion in septic shock patients: a prospective, randomized clinical trial. Nephrol Dial Transplant 2001; 16:320-327.

28 Tonelli M, Manns B, Wiebe N, Shrive F, Pannu N, Doig C, Klarenbach S: Continuous Renal Replacement Therapy in Adult Patients with Acute Renal Failure: Systematic Review and Economic Evaluation. Ottawa, Canadian Agency for Drugs and Technologies in Health, 2007.

29 Kumar VA, Craig M, Depner TA, Yeun JY: Extended daily dialysis: a new approach to renal replacement for acute renal failure in the intensive care unit. Am J Kidney Dis 2000;36:294-300.
30 Berbece AN, Richardson RM: Sustained low-efficiency dialysis in the ICU: cost, anticoagulation, and solute removal. Kidney Int 2006;70:963-968.

-31 Kielstein JT, Kretschmer U, Ernst T, Hafer C, Bahr MJ, Haller H, Fliser D: Efficacy and cardiovascular tolerability of extended dialysis in critically ill patients: a randomized controlled study. Am J Kidney Dis 2004;43: 342-349.

>32 Baldwin I, Bellomo R, Naka T, Koch B, Fealy $\mathrm{N}$ : A pilot randomized controlled comparison of extended daily dialysis with filtration and continuous veno-venous hemofiltration: fluid removal and hemodynamics. Int J Artif Organs 2007;30:1083-1089.

33 Gashti CN, Salcedo S, Robinson V, Rodby RA: Accelerated venovenous hemofiltration: early technical and clinical experience. Am J Kidney Dis 2008;51:804-810.

34 Schiffl H, Lang SM, Fischer R: Daily hemodialysis and the outcome of acute renal failure. N Engl J Med 2002;346:305-310.

>35 Ronco C, Bellomo R, Homel P, Brendolan A, Dan M, Piccinni P, La Greca G: Effects of different doses in continuous veno-venous haemofiltration on outcomes of acute renal failure: a prospective randomised trial. Lancet 2000;356:26-30

-36 Saudan P, Niederberger M, De Seigneux S, Romand J, Pugin J, Perneger T, Martin PY: Adding a dialysis dose to continuous hemofiltration increases survival in patients with acute renal failure. Kidney Int 2006;70:13121317.

-37 Bouman CS, Oudemans-Van Straaten HM, Tijssen JG, Zandstra DF, Kesecioglu J: Effects of early high-volume continuous venovenous hemofiltration on survival and recovery of renal function in intensive care patients with acute renal failure: a prospective, randomized trial. Crit Care Med 2002; 30:2205-2211.

-38 Tolwani AJ, Campbell RC, Stofan BS, Lai KR, Oster RA, Wille KM: Standard versus highdose CVVHDF for ICU-related acute renal failure. J Am Soc Nephrol 2008;19:12331238

39 Palevsky PM, Zhang JH, O'Connor TZ, Chertow GM, Crowley ST, Choudhury D, Finkel K, Kellum JA, Paganini E, Schein RM, Smith MW, Swanson KM, Thompson BT, Vijayan A, Watnick S, Star RA, Peduzzi P: Intensity of renal support in critically ill patients with acute kidney injury. N Engl J Med 2008;359:7-20.

40 Cho KC, Himmelfarb J, Paganini E, Ikizler TA, Soroko SH, Mehta RL, Chertow GM: Survival by dialysis modality in critically ill patients with acute kidney injury. J Am Soc Nephrol 2006;17:3132-3138.

-41 Seabra VF, Balk EM, Liangos O, Sosa MA, Cendoroglo M, Jaber BL: Timing of renal replacement therapy initiation in acute renal failure: a meta-analysis. Am J Kidney Dis $2008 ; 52: 272-284$ 
42 Daud KM, Leong G, Visvanathan R: Acute dialytic support for the critically ill: continuous venovenous haemodialysis versus continuous venovenous haemofiltration. Int Med J 2006;13:37-42.

-43 Haase M, Bellomo R, Baldwin I, HaaseFielitz A, Fealy N, Davenport P, Morgera S, Goehl H, Storr M, Boyce N, Neumayer HH: Hemodialysis membrane with a high-molecular-weight cutoff and cytokine levels in sepsis complicated by acute renal failure: a phase 1 randomized trial. Am J Kidney Dis 2007; 50:296-304.
44 Morgera S, Haase M, Kuss T, Vargas-Hein O, Zuckermann-Becker H, Melzer C, Krieg H, Wegner B, Bellomo R, Neumayer HH: Pilot study on the effects of high cutoff hemofiltration on the need for norepinephrine in septic patients with acute renal failure. Crit Care Med 2006;34:2099-2104.

45 Humes HD, Fissell WH, Weitzel WF: The bioartificial kidney in the treatment of acute renal failure. Kidney Int Suppl 2002:121125.
46 Humes HD, Fissell WH, Weitzel WF, Buffington DA, Westover AJ, MacKay SM, Gutierrez JM: Metabolic replacement of kidney function in uremic animals with a bioartificial kidney containing human cells. Am J Kidney Dis 2002;39:1078-1087.

47 Tumlin J, Wali R, Williams W, Murray P, Tolwani AJ, Vinnikova AK, Szerlip HM, Ye J, Paganini EP, Dworkin L, Finkel KW, Kraus MA, Humes HD: Efficacy and safety of renal tubule cell therapy for acute renal failure. J Am Soc Nephrol 2008;19:1034-1040.

\title{
Editorial Comment
}

\author{
M. El Nahas, Sheffield
}

This excellent review by Fieghen, Wald and Jaber from Toronto and Boston highlights recent advances in the classification of AKI whilst drawing attention to the limitations of clinical trials in the field. It also brings to the reader's awareness the recent interest in the predictive value of a number of biomarkers including NGAL, IL-18 and KIM-1. These biomarkers have been put forward as early diagnostic and prognostic indicators in AKI.

More recently, Jaber's group in Boston has reported on the influence of patients' genotype on outcomes in AKI. They noted a relationship to adverse outcome of a nonsynonymous polymorphism in the coding region of the HIF-1 $\alpha$ gene where a $\mathrm{C}$ to $\mathrm{T}$ substitution occurs at position +85 in exon 12 [Kolyada et al., 2009]. This association warrants further investigation.

In their minireview, the authors thoroughly and critically review a number of clinical trials of pharmacological interventions as well as those based on replacement therapy modalities or intensity in AKI. Most of these in- tervention trials are negative as they fail to show significant advantage. This may be due in part to the fact that clinical trials in AKI are very difficult to conduct due to the heterogeneity of the patients involved and associated comorbidities.

Recent interest has also emerged in the impact AKI may have on the incidence of chronic kidney disease as well as on the acceleration of the progression of established chronic kidney disease to end-stage renal disease. This is likely to be particularly relevant in the elderly whose recovery from AKI is often limited and may precipitate end-stage renal disease.

\section{Reference}

Kolyada AY, Tighiouart H, Perianayagam MC, Liangos O, Madias NE, Jaber BL: A genetic variant of hypoxia-inducible factor-1alpha is associated with adverse outcomes in acute kidney injury. Kidney Int 2009; $75: 1322-1329$ 